\title{
COR V2: Teaching observational research with multimedia courseware
}

\author{
DAWN G. BLASKO, VICTORIA A. KAZMERSKI, and CARLA N. TORGERSON \\ Penn State Erie, Behrend College, Erie, Pennsylvania
}

\begin{abstract}
Courseware for Observational Research (COR Version 2) is an interactive multimedia program designed to teach the foundation of the scientific method: systematic observation. COR uses digital video with interactive coding to teach basic concepts, such as creating precise operational definitions; using frequency, interval, and duration coding; developing sampling strategies; and analyzing and interpreting data. Through lessons, a case study, and laboratory exercises, it gradually scaffolds students from teacherdirected learning into self-directed learning. The newest addition to COR is a case study in which students work collaboratively, using their own observations to make recommendations about a child's disruptive behavior in an after-school program. Evaluations of the lessons showed that classes using COR received better grades on their field observations than did those using methods that are more traditional. Students' confidence and knowledge increased as they moved through each section of the program.
\end{abstract}

Statistics and research methods are undoubtedly some of the most difficult courses to teach in science education. This may be more pronounced in psychology, where many students enter the major motivated by the desire to "help people." This people-based orientation is often at odds with the more mathematical and science-based approach of psychology training, and the resulting mismatch between the goals of students and the goals of their faculty can have negative consequences for both. Therefore, it is in everyone's best interests to devise ways to teach these topics while promoting a positive attitude among the students (Blasko, Kazmerski, Corty, \& Kallgren, 1998). This is one of the major goals of the development of Courseware for Observational Research (COR).

In designing $\mathrm{COR}$, we incorporated several pedagogical innovations derived from basic research in cognitive psychology, including the promotion of active learning in authentic contexts, increasing depth of processing, and encouraging metacognitive awareness (Alexander \& Schwanenflugel, 1994; Craik \& Lockhart, 1972; Johnson \& Johnson, 1999). One factor that influences both the degree of learning and the student's attitude about a course is the context of that learning. That is, when information is presented in a meaningful context, students are more

Financial support came from the Penn State Faculty Initiative Technology program for the early stages of development, and student programming support was provided by Penn State Erie Undergraduate Research Grants. We thank Carol Dwyer and Jacob Cornwall for programming and instructional design support and Chris Majerik and Matthew Stevenson for assistance with video production. Corresponding concerning this article should be addressed to D. G. Blasko, Humanities and Social Sciences, Penn State Erie, 5091 Station Road, Erie, PA 16563 (e-mail: dawnblasko@psu.edu). likely to see the information as relevant and applicable to their everyday lives. Meaningful information is also easier to organize and more likely to be recalled (Thompson, Skowronski, Larsen, \& Betz, 1996).

Research has also supported the notion that students who are actively involved in problem solving and are challenged to figure out the answers to a problem will be much more likely to understand and recall the information than those that passively listen to lectures or read their text (Miserandino, 1999). One way of increasing student activity and decreasing faculty workload is using collaborative learning. Students can learn much from their peers, and when they are in the position to teach concepts to their peers, it enhances their metacognitive awareness (Johnson \& Johnson, 1999). Students also provide needed emotional support when concepts are difficult and frustration builds. In the development of COR, we took the perspective that it can be valuable to have students work in teams toward a common goal on a problem that is challenging enough to require considerable effort, while also being interesting and meaningful.

Observational research is one of the most commonly used research methods across many disciplines and settings (e.g., school psychology, human services and clinical settings, animal behavior, and workplace and safety analysis). However, its coverage in the typical psychology research methods book is weak at best. To our knowledge, there are no easily available software programs to supplement a basic research text. We teach observational research for approximately one third of our four-credit basic research methods class. In this unit, we address general course learning objectives, such as creating an operational definition, understanding the importance of reliability and validity, developing a testable hypothesis, and understanding 
Table 1

Topics Covered by COR

\begin{tabular}{lccc}
\hline \multicolumn{1}{c}{ Topics } & Lessons & Case Study & Laboratory \\
\hline Overview & Lesson 1 & & \\
Steps of the scientific method & Lesson 1 & + & + \\
External validity: Field vs. laboratory research & Lesson 1 & + & \\
Participant vs. naturalistic observation & Lesson 1 & & \\
Developing a hypothesis & Lesson 1 & + & + \\
Operational definitions & Lesson 1 & + & + \\
Coding techniques: Frequency, interval, duration & Lesson 2 & + & + \\
Sampling techniques: Event, individual, time & Lesson 3 & + & + \\
Interrater reliability: Percent correct and Cohen's kappa & Lesson 4 & + & + \\
Hypothesis testing: Chi square & Lesson 5 & + & + \\
Statistical significance vs. practical significance & Lesson 5 & + & \\
Writing reports: & & & + \\
$\quad$ APA style & Lesson 6 & & + \\
Clinical report & & + & + \\
Ethical issues & & + & \\
\hline
\end{tabular}

the logic of hypothesis testing. In addition, we may discuss the issue of ethics in research and practice and the issue of theoretical and/or practical importance versus statistical significance. In our course, the use of COR culminates in a field study in which students design and conduct their own observations at the local zoo.

Conducting live observations certainly has a number of benefits, but it also has serious drawbacks. Conducting animal observations requires either an animal laboratory, which is often cost prohibitive for smaller schools, or access to a local zoo. When students go to the zoo, they often find that animals fail to perform the predicted behavior, sleep through the observation, or are off display at the time of the visit. There are also ethical issues involved in observing animals. Similar problems exist in observing children. Observing children in public places is often frightening to parents and, therefore, prohibited without parental consent. In contrast, our digital video subjects are always awake and behaving in meaningful ways and, therefore, can provide a critical degree of practice on different behaviors and different settings.

\section{Description of COR}

We began by creating a large video library of digital video clips ranging in length from 1 to $5 \mathrm{~min}$, which involved a variety of subject populations (e.g., fish, birds, hamsters, flamingos, monkeys, cars, boats, children, and adults) in a variety of interesting activities (e.g., feeding, grooming, driving, gesturing, or socializing). This makes the program highly flexible for the instructor, who can use any of the videos to illustrate key concepts or to compare applications across situations. Given such a wide choice of possible situations, students are almost certain to find something of particular personal interest.

COR consists of three major modules: lessons, case study, and laboratory. Table 1 shows an outline of the content. The overarching pedagogical strategy is to move the students from teacher-directed learning in the lessons module, to increasingly student-directed learning in the case study and laboratory modules.

The lessons module includes an overview of systematic observation, coding techniques, sampling strategies, inter- rater reliability, and basic hypothesis testing. In each lesson, a short video is used to present observational settings that are realistic and have been carefully chosen for their relevance to a particular concept. We have used the lessons as the basis for instructor-led lectures in which the students practice the techniques at their desk or model the coding at the instructor's computer. "Dr. Wellington," a virtual consultant in the program, is introduced in the first lesson as an expert in observational research. For each lesson, a sample operational definition and a data set are provided, which are referred to as Dr. Wellington's data. Comparisons can then be made with data collected by the students.

After the presentation of the topics in the lessons, students go on to practice these concepts with more independence in a guided case study environment. The case study is about a young girl called Sarah, who may be removed from her after-school program because of her aggressive behavior. Students observe Sarah in two settings to determine whether she is indeed more aggressive than her age-matched peers. Figure 1 shows the opening screen of the case study. Here, students once again encounter their virtual consultant Dr. Wellington and can hear from the teachers and parents. In the case study, students work in teams to develop an operational definition for aggressive behavior. They design a coding sheet, determine interrater reliability, and interpret and write up their results. They are guided in this process by Dr. Wellington's advice. She provides reviews of concepts through interactive quizzes that require the students to enter their decisions into the program before advancing in the program. The students using the case study are in a type of apprenticeship situation (Gardner, 1991) in which they have the model and the support of both a real and a virtual instructor, but they are also expected to make most decisions for themselves. All the students' work is saved in an XML (extensible markup language) file, and when the students exit and reenter the program, they can pick up where they left off. For example, Figure 2 shows the point in the case study at which Dr. Wellington prompts students to design their observation and develop an appropriate coding sheet. Students decide how many children to observe and the length of the appropriate interval and enter it into the program. ${ }^{1}$ The pro- 


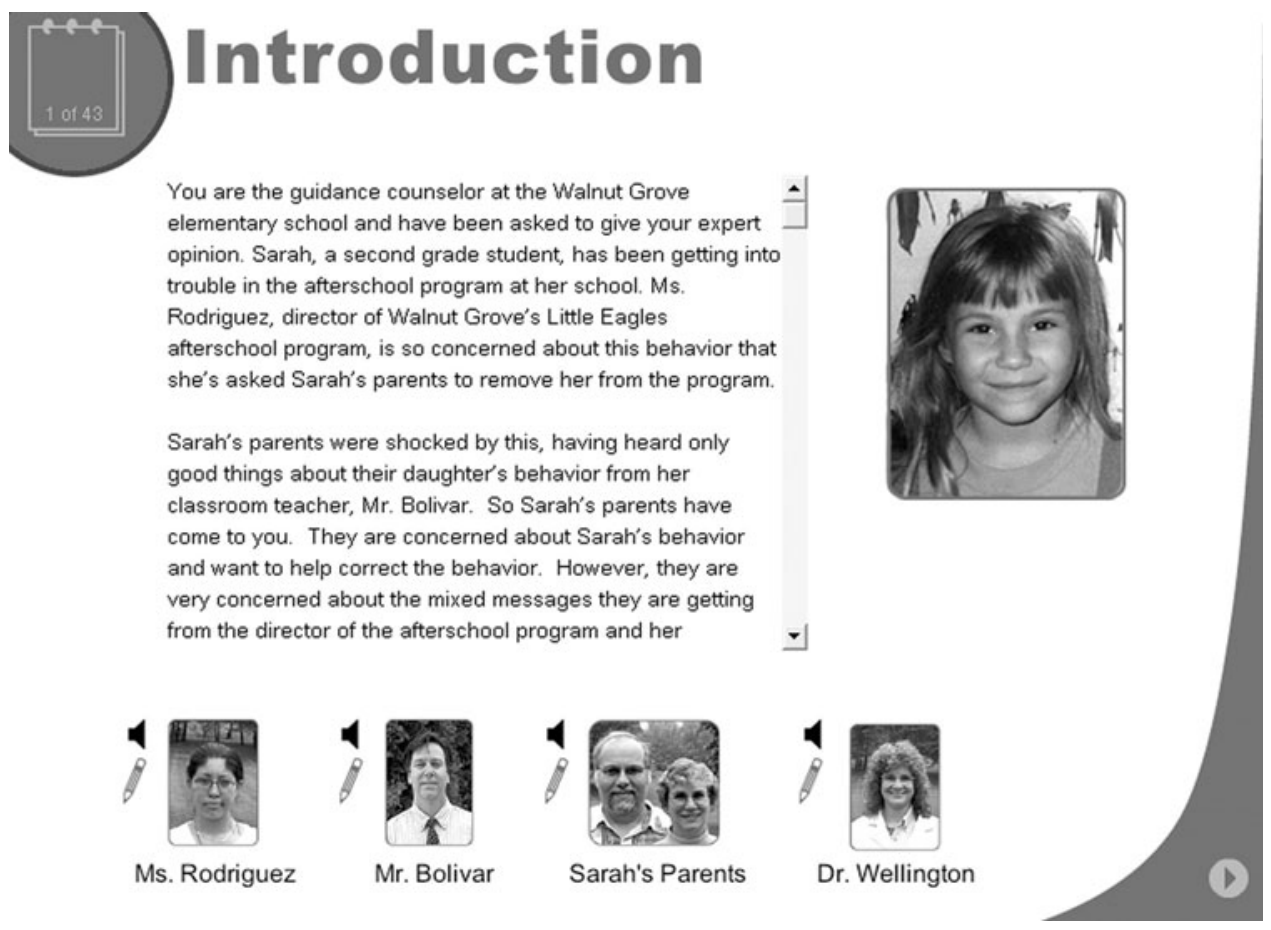

Figure 1. The opening screen of the case study, in which students meet each character.

gram checks their work before allowing them to go on. This information is then used to create a personalized coding sheet for each team of students. Throughout this work, the students may refer back to the lessons to review the previ- ously covered information. Next, the students work with the concepts more independently in the laboratory module, which provides a selection of videos that present examples of various human and animal behaviors. In this
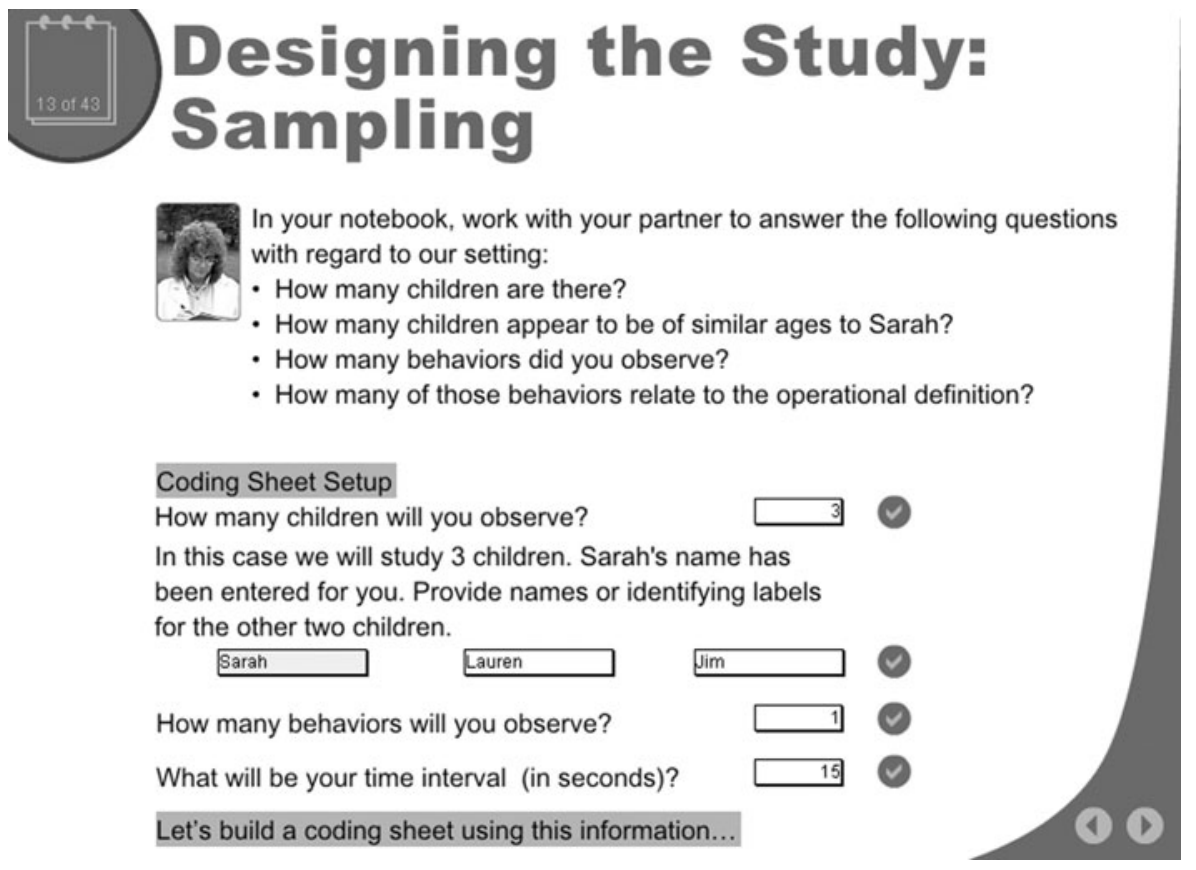

Figure 2. The point in the case study at which Dr. Wellington prompts students to design their observation and develop an appropriate coding sheet. 
module, there is very little explicit guidance; however, links are provided to go back to the lesson material to review the concepts.

\section{The Programming Environment and Use of Technology}

COR Version 2 has been developed using Macromedia Director. Director was chosen because it has the potential to be used cross-platform and allows integration of digital video, a high level of interactivity, and easy storage of student data. In the case study, it is especially important to track student input so that they can get appropriate feedback and can pick up where they left off if they need to leave. Integration of videos is a key to COR's ability to assist students in learning observational research skills. By tracking the timing of the video, we are able to show data being written on the computer-coding sheet as if the expert was coding the video. This creates a very powerful learning tool for students. We also capitalized on the ability of Director to read external files to create a program that can be easily customized by the instructor. Students can create new files and save a data file that can be moved from machine to machine. When the students reopen their files later, the program restarts where they left off, ensuring that they do not skip any important steps in their data collection. An instructor file is included that is populated with data, so that instructors can move anywhere to review the case study. By entering the program in administration mode, instructors are also able to change glossary definitions and add terms. ${ }^{2}$ At this point, the only way for the instructor to add a video is to edit the Director files. However, in future versions, we hope to make this process part of the editing functions of the program.

\section{Evaluation Results}

The basic lessons module is similar to that of Version 1 of COR, where we conducted extensive evaluations (see Kazmerski \& Blasko, 1999, for details). To summarize briefly, introductory psychology students taught observa- tional research with COR obtained significantly higher scores on their research projects than those using traditional lecture methods. On the basis of feedback from students and reviewers, we undertook an extensive revision that culminated in COR Version 2.

In the Spring 2003 semester, COR V2 was used for the first time in the Basic Research Methods class at Penn State Erie. Because we had previously evaluated the lesson material, here we focused our attention on the new case study. Students $(N=23)$ rated their confidence in performing 10 tasks, such as chi-square analysis and interrater reliability, on a scale of 0 (not at all confident) to 100 (extremely confident) before and after using the case study. The composite of the 10 topics is shown on the left of Figure 3. The results showed significant increases in confidence across all 10 topics, as well as in the composite score $[t(21)=11.9, p<.0001]$. Although less dramatic, there was also a significant increase in the test scores of students after completing the case study $[t(22)=$ $4.7, p<.001]$.

In Fall 2003, students evaluated the full program. The students were given a multiple-choice quiz covering the content of the chapter in their text at four times during the unit: (1) after reading the chapter, prior to covering the material in class; (2) after covering the materials in the Lessons unit in class; (3) after working through the Case Study independently; and (4) after working through the Laboratory section and finishing a complete observational field study at the local zoo. There were 19 questions on the quiz; the material covered was the same on each exam, although the questions were reworded for each quiz. Of these, 11 questions covered the content presented in COR, and 8 tested material that was presented in the text, but not in COR. In addition, the students were asked to rate their confidence along 10 dimensions in each quiz. Usability was assessed at the final administration.

The students' performance on the multiple-choice content questions improved across the four administrations $\left[F(3,72)=17.75, \eta^{2}=.43, p<.001\right]$. The linear trend

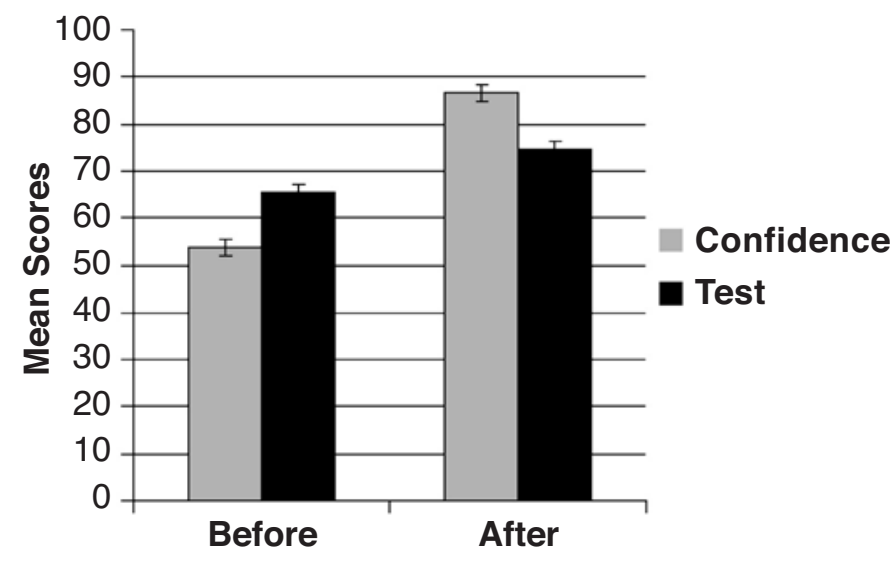

Figure 3. Students' mean confidence ratings and mean test scores before and after using the case study. Error bars show the standard error of the mean. 
across the four test times was reliable $[F(1,24)=32.77$, $\left.\eta^{2}=.58, p<.001\right]$. Pairwise comparisons revealed significant increases from Times 1 to 2 and from Times 3 to 4 , but not from Times 2 to 3 . To better understand the impact of COR, an analysis was conducted using the percent correct on items that were covered in COR on each of the four quizzes and the percent correct on items covered only in the text. These were then analyzed in a 2 (material location: COR/text) $\times 4$ (quiz administration) analysis of variance (ANOVA). This ANOVA revealed a significant interaction of location and quiz $\left[F(3,72)=8.99, \eta^{2}=.27, p<\right.$ $.001]$. A follow-up analysis showed that the quiz scores improved for the items covered in $\operatorname{COR}[F(3,72)=27.61$, $\left.\eta^{2}=.54, p<.001\right]$, but not for the items covered only in the text $\left[F(3,72)=0.24, \eta^{2}=.01, p=.87\right]$. These scores are presented in Figure 4. We also measured the students' confidence levels and found that the students felt much more confident in their skills at the end of the course than at the beginning $\left[F(3,72)=48.81, \eta^{2}=.67, p<.0001\right]$. To summarize, the students' performance on the CORrelated questions on the quizzes improved over each quiz. In contrast, their performance on the text-related material was stable across the quizzes. Confidence ratings on performing an observational research project also improved as they used COR.

Usability. The students rated COR's usability (Alessi $\&$ Trollip, 2001) for the lessons, case study, laboratory, library, and glossary. Overall, $88 \%$ of the students found COR very easy to use. Most students found COR "somewhat helpful" or "very helpful" in understanding observational research (lessons, 92\%; case study, 88\%; laboratory, $88 \%$ ).

Focus groups. Focus groups were conducted with the 25 students in the Fall 2003 class. They were interviewed by one of the authors (D.G.B.), who was not the course instructor and did not know most of the students. Conversa- tions were tape recorded, transcribed, and analyzed for thematic content. The students felt that navigation through the program was easy and the presentation of material was clear. They noted the repetition and elaboration of concepts at each stage of the program and how the program shifted from more reliance on the teacher for the explanation of concepts toward students' needing to use this information on their own. A number of students (60\%) thought it was helpful that they were "forced" to get the answer right in the case study before going on, because they admitted that otherwise they would have advanced to the next page without necessarily understanding the material.

Consistent with the results of the data described above, the consensus of the group was that they understood observational techniques much better after using COR. The major strength mentioned in each focus group was working through the case study. It made studying research methods "less boring" and seem more "real" and "important." They also mentioned that it strongly reinforced their understanding of basic hypothesis testing and the chi-square statistic. All the students enjoyed the collaborative aspects of the program and mentioned that working with a partner allowed them to "support each other," especially when they were confused or made mistakes. This was in stark contrast to their negative feelings about most group work.

When students were asked whether they had typically used software that came with their text, $90 \%$ reported that they had received a courseware CD that they had never opened. The major reason was that most multimedia software merely repeats the material in the book, so it becomes a very low priority. One hopeful note was that virtually all the students $(96 \%)$ reported that they would use software on their own if it provided new material and if they felt that it would improve their learning. This was the case with COR. All of the students claimed to have accessed COR off the school network out of class, despite the fact

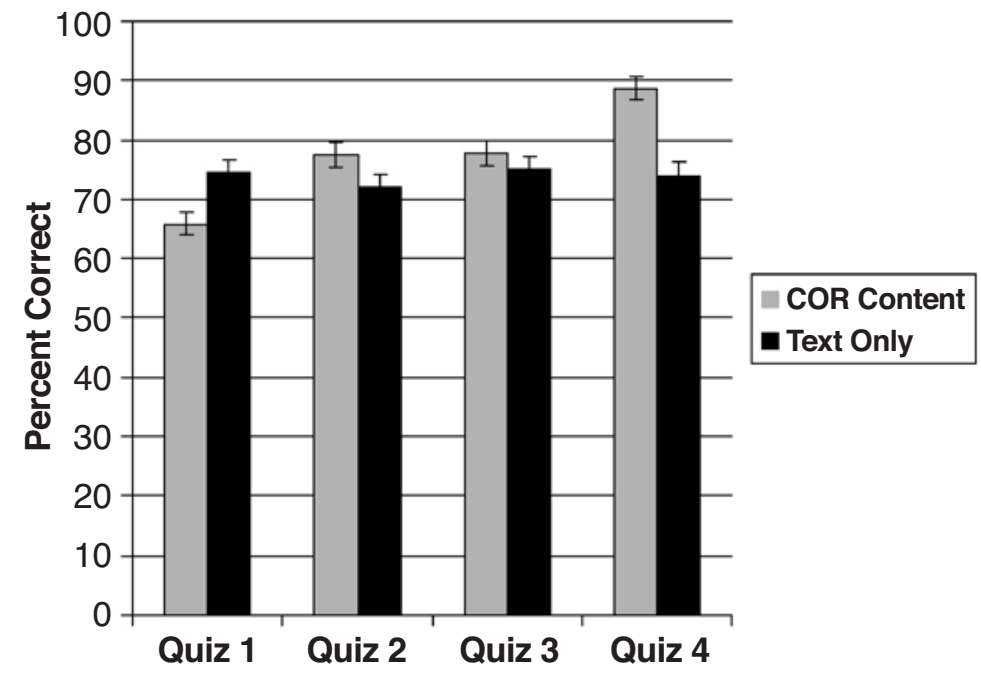

Figure 4. Students' mean quiz scores for questions covered in the COR program and questions covered only in the text at each of the four test times. Error bars show the standard error of the mean. 
that it was not required. They used it to check their procedures for their field study, to practice coding, and to write up their reports. Over $90 \%$ of the students reported reviewing COR in the process of studying for the exam.

Although the comments were primarily positive, the students noted room for improvement. The most common suggestion for improvement (28\%) was to provide more examples of how to deal with complex issues, such as calculating reliability with more than two coders and combining coding and sampling techniques. They also wanted more examples of analysis strategies $(20 \%)$, especially in the case of more than two groups and unbalanced base rates. Three students mentioned that they would like to be able to maximize the screen to cover the entire desktop. Two students asked for a programmable timer that they could set to beep at a particular time interval in the laboratory. These suggestions are on our list for the next version.

\section{Availability and Future Work}

COR V2 is now being made available to a group of beta testers at no charge. It has been tested on a variety of Windows-based machines and operating systems, including Windows 2000, Windows ME, and Windows XP. It requires the installation of the QuickTime player, Version 5.0.1 or higher. COR can be installed and used across a network. If you are interested, contact the authors or sign up as a beta user at the COR Web site at http://www.cor. psu-erie.bd.psu.edu/cor/. After evaluations with faculty outside of Penn State, one goal is to develop a supplemental workbook for faculty and students. This will include ideas for ways to use the program in a variety of courses at different levels. In addition, we will be working on a version for the Mac platform, as well as investigating the feasibility of delivering portions of the program over the Web, using streaming video.

\section{REFERENCES}

Alessi, S. M., \& Trollip, S. R. (2001). Multimedia for learning: Methods and development (3rd ed.). Boston: Allyn \& Bacon.

Alexander, J. M., \& Schwanenflugel, P. J. (1994). Strategy regulation: The role of intelligence, metacognitive attributions, and knowledge base. Developmental Psychology, 30, 709-723.

Blasko, D. G., Kazmerski, V. A., Corty, E. W., \& Kallgren, C. A. (1998). Courseware for observational research (COR): A new approach to teaching naturalistic observation, Behavior Research Methods, Instruments, \& Computers, 30, 217-222.

Craik, F. I. M., \& Lockhart, R. S. (1972). Levels of processing: A framework for memory research. Journal of Verbal Learning \& Verbal Behavior, 12, 599-607.

GARDNER, H. (1991). The unschooled mind: How children think and how schools should teach. New York: Basic Books.

Johnson, D. W., \& Johnson, R. T. (1999). Learning together and alone: Cooperative, competitive, and individualistic learning (5th ed.). Boston: Allyn \& Bacon.

KaZmerski, V. A., \& Blasko, D. G. (1999). Teaching observational research in introductory psychology: Computerized and lecture-based methods. Teaching of Psychology, 26, 295-298.

Miserandino, M. (1999). Those who can do: Implementing active learning. In B. Perlman, L. I. McCann, \& S. H. McFadden (Eds.), Lessons learned: Practical advice for the teaching of psychology (Vol. 1, pp. 109114). Washington, DC: American Psychological Society.

Thompson, C. P., Skowronski, J. J., Larsen, S. F., \& Betz, A. (1996) Autobiographical memory: Remembering what and remembering when. Mahwah, NJ: Erlbaum.

\section{NOTES}

1. At this point in development, the case study guides students toward interval coding to simplify the calculation of interrater reliability. In the lessons, we discuss a variety of coding techniques, and in the laboratory, students can choose the most appropriate technique.

2. An instructor with some knowledge of HTML or XML can also change Dr. Wellington's coding and operational definitions in the lessons by modifying the XML files in the Data folder of COR.

(Manuscript received November 16, 2003; revision accepted for publication April 6, 2004.) 